\title{
SYNTHESIS OF SUBSTITUTED BENZIMIDAZOLONES AND THEIR BIOLOGICAL ACTIVITY
}

\section{M.D. Tsymliakov' ${ }^{1}$, A.I. Maksutova', E.V.Sokolova ${ }^{2}$, V.G. Klochkov ${ }^{2}$}

${ }^{1}$ Department of Chemistry, Lomonosov Moscow State University, 119234, Russia, Moscow, Leninskie Gory St., 1

2Department of Pharmacology and bioinformatics, Volgograd State Medical University, 400131, Russia, Volgograd, Ploshchad pavshikh borcov, 1

DOI: 10.19163/MedChemRussia2021-2021-403

E-mail: tsymmd@gmail.com

In order to search for new biologically active heterocyclic compounds, a number of substituted benzimidazolones were obtained. Multi-stage synthesis was now possible due to the development of regioselective reduction methods for dinitroarenes in our scientific group, which led to non-symmetrical 1-substituted 5-nitro benzimidazolones (Figure 1).

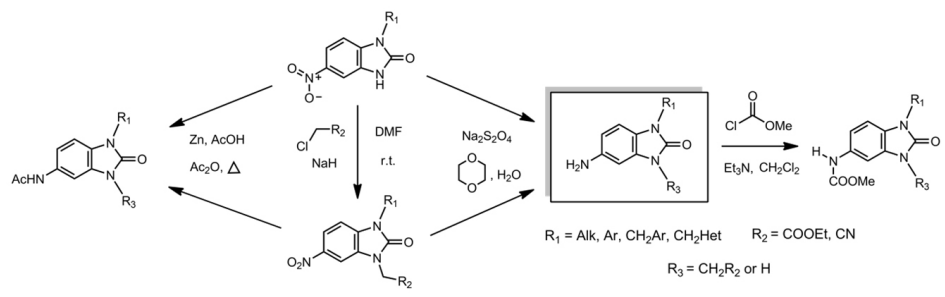

Fig. 1. Reaction scheme for the synthesis of target library

In vitro screening results of highlighted in Figure 1 derivatives can be seen in Figure 2. Anti-inflammatory activity associated with toll-like receptors (TLRs) inhibition was investigated on rat macrophages. Inhibition of TLRs is important in treatment of Alzheimer's disease, atherosclerosis and even COVID-19. Most of the compounds have shown significant activity (more than $40 \%$ inhibition) with a maximum of $82 \%$ for 2 , being completely non-toxic to investigated cells.
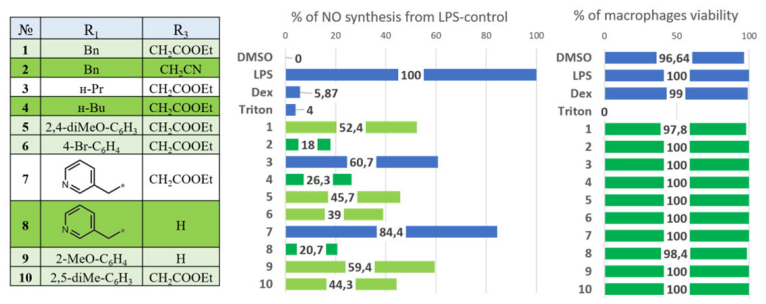

Dex = dexamethasone; LPS = lipopolysaccharide, TLR ligand; Triton = Triton X100 detergent

Fig. 2. Anti-inflammatory activity of synthesized compounds in $100 \mu \mathrm{M}$ concentration.

Synthetic part of this work was supported by the Russian Foundation for Basic Research (Project 20-03-00915). 